\title{
Weighted needle pinprick sensory thresholds: a simple test of sensory function in diabetic peripheral neuropathy
}

\author{
A W Chan, I A MacFarlane, D Bowsher, J A Campbell
}

\begin{abstract}
A simple device is described, consisting of 12 weighted 23 gauge disposable needles $(0.2$ to $5.2 \mathrm{~g})$, for testing sensation in busy diabetic clinics. The pinprick sensory threshold (PPT) is the lightest weighted needle which consistently elicits a sharp sensation. The subjects were 48 healthy controls (hospital stafi), 44 diabetic patients without neuropathic symptoms, and 35 diabetic patients with chronic painful neuropathy. In the controls, the mean PPT from the right hand and foot obtained on two test occasions a week apart did not differ significantly. In diabetic patients without symptomatic neuropathy, the mean PPT in the right hand and right foot were significantly higher than in the controls. The diabetic patients with painful neuropathy had clearly increased mean PPT in the right hand and foot compared with controls. Marstock thermal limen in diabetic patients with painful neuropathy correlated significantly with PPT determinations. PPT and thermal thresholds probably give comparable information on small fibre dysfunction in diabetic patients with symptomatic neuropathy. Compared with thermal threshold determinations, however, the weighted needle apparatus is inexpensive, simple, and rapid to use.
\end{abstract}

In diabetes mellitus loss of pain and temperature sensation with or without spontaneous neuropathic pain ${ }^{12}$ is due to damage of small myelinated A-delta and smaller unmyelinated C-fibres. Individuals with insensitive feet are at increased risk of developing plantar ulceration induced by repeated mechanical (pressure) injury. ${ }^{3}$ Loss of nociceptive C-fibre function also impairs neurogenic inflammation and wound healing. ${ }^{4}$ Routine neurological examination may identify diabetic patients with impaired cutaneous sensation, but qualitative changes in physical signs may be difficult to interpret and depend on the examiner's technique and experience, which vary greatly. Several expensive methods are available for quantitative assessment of small fibre function, including pinch or pressure algometers ${ }^{56}$ and Marstock thermostimulators. ${ }^{7-10}$ Pressure algometers can be applied only to areas where a skin fold can be separated from the underlying tissues and thresholds are affected by the rate of application of the pinch stimulus which is difficult to standardise. Estimation of thermal thresholds with Marstock devices may take 15 minutes at each examination site ${ }^{910}$ and therefore measurements at more than two sites become laborious and time-consuming.

There is a need for a quick method of sensory assessment in the busy diabetic clinic which will identify patients with insensitive feet who are at risk of developing foot ulceration. We tested a simple, inexpensive and reliable weighted pinprick sensory threshold (PPT) device, which is suitable for outpatient use. No published data exist evaluating this technique in either normal subjects or people with peripheral neuropathy. We present weighted pinprick sensory thresholds from a large number of healthy subjects and diabetic patients with and without symptomatic neuropathy.

\section{Patients and methods}

Weighted needle pinprick sensory thresholds apparatus

Pinprick sensory thresholds were obtained by means of 12 disposable $25 \mathrm{~mm}, 23$-gauge needles which moved freely out of a $2 \mathrm{ml}$ plastic syringe barrel (figure). The 12 needles were weighted to produce a graded series of pinprick stimuli (from 0.2 to $5.2 \mathrm{~g}$ ); the steps were determined after a large number of trials on normal laboratory personnel. They were applied perpendicularly to the skin on the dorsum of both hands in the middle of the anatomical snuff box (between the first two metacarpals) and dorsum of both feet in the proximal part of the first intermetatarsal space. The technique is easy to learn, and the results are simple to record. To produce consistent pinprick threshold determinations, three important practical points should be adhered to. Firstly, the weighted needle must be brought in to gentle contact with the skin. In this way, the pinprick sensation is produced only by the weight of the needle resting on the skin. The needles should be applied in an ascending and descending manner, according to the method of limits, ${ }^{6}$ over a skin area of about $1 \mathrm{~cm}^{2}$. The pinprick threshold (PPT) is the lightest weighted needle which consistently produced a sharp sensation. Secondly, the test subject must disregard any tactile sensation which may be elicited by the lightest weighted needles and report only the perception of pinprick sensation. Thirdly, pinprick sensation may persist for a few seconds and therefore to avoid confusion successive weighted needles must not be applied too quickly. Each pinprick 


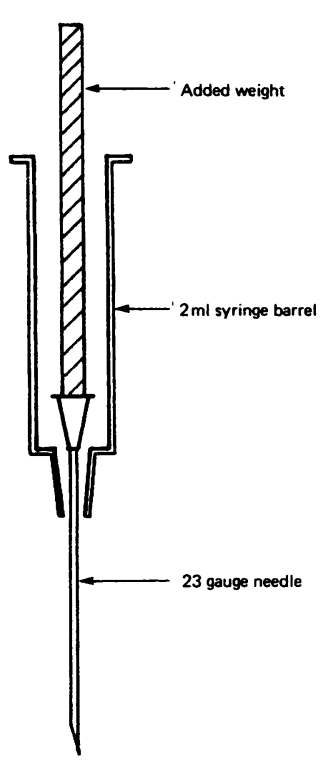

Figure Weighted needle pinprick sensory threshold apparatus. Twelve 23gauge needles individually weighted to produce stimuli $0 \cdot 2.0 \cdot 65,1 \cdot 15$, $1 \cdot 6,1 \cdot 8,2 \cdot 0,2 \cdot 4,2 \cdot 8,3 \cdot 2$ $3 \cdot 8,4 \cdot 4,5 \cdot 2 \mathrm{~g}$. Each weighted needle moves freely within $2 \mathrm{ml}$ plastic syringe barrel. following graded pinprick

sensory threshold determination took about one to two minutes, and examination of all four standard sites took a total of 10 minutes. For reasons of hygiene and to eliminate the problem of cross infection fresh sterile needles were used for each subject. Therefore, the resulting cost of each examination is a maximum of $f 0.20$, which is the price of 12 disposable 23-gauge needles (in mid 1990).

\section{Subjects studied (table 1)}

Reference values for weighted pinprick sensory thresholds were obtained from 48 healthy controls (23 men and 25 women; mean age $47 \cdot 8$ years) who were recruited from the hospital staff and their relatives. To assess reproducibility all 48 control subjects were tested on two occasions, about one week apart. Pinprick sensory thresholds were obtained from 35 diabetic patients (27 men and eight women; mean age 54.3 years) with chronic painful peripheral neuropathy, recruited from the diabetes centre at Walton Hospital. All patients had neruopathic symptoms, including burning and shooting leg pains and signs of sensory impairment including diminished light touch (cotton wool), vibration (tuning fork), and pinprick (disposable needle) sensation. Other causes of painful, peripheral neuropathy were carefully excluded by normal serum chemistry, B12 and folate concentrations, and thyroid and liver function tests. The mean duration of painful neuropathic symptoms was 3.6 years (range $1-13$ years). Pinprick sensory thresholds were also obtained from another 44 consecutive diabetic patients ( 24 men and 20 women; mean age $50 \cdot 1$ years) without symptoms of neuropathy who were attending a follow up diabetic clinic. The mean ages of the controls and the two groups of diabetic patients were similar, and the duration of diabetes in the patients with painful neuropathy and asymptomatic patients did not differ significantly $(10.4$ years, SD $7 \cdot 9 v 9 \cdot 5$ years, SD 7.7, respectively). In the patients with painful diabetic neuropathy pinprick sensory thresholds were compared with tests of thermal sensitivity (cold-warm limen) obtained with a Marstock thermostimulator applied to the dorsolateral part of the foot (under the lateral malleolus) (Somedic, Sweden). ${ }^{7}$ Informed consent was obtained from all subjects, and the study was approved by the Walton Hospital ethical committee.

\section{Statistical analysis}

In the data from the control subjects, the paired $t$ test was used to evaluate differences in pin-

Table 1 Demographic details of subjects studied

\begin{tabular}{llll}
\hline & $\begin{array}{l}\text { Controls } \\
(n=48)\end{array}$ & $\begin{array}{l}\text { Asymptomatic diabetic } \\
\text { patients }(n=44)\end{array}$ & $\begin{array}{l}\text { Painful diabetic } \\
\text { neuropathy }(n=35)\end{array}$ \\
\hline Men & 23 & 24 & 27 \\
Women & 25 & 20 & 8 \\
$\begin{array}{l}\text { Age (SD, range) (years) } \\
\text { Duration (SD, range) of } \\
\text { diabetes (years) }\end{array}$ & $47 \cdot 8(17 \cdot 6,24-83)$ & $50 \cdot 1(21 \cdot 5,17-80)$ & $54 \cdot 3(12 \cdot 0,27-79)$ \\
$\begin{array}{l}\text { No insulin treated } \\
\text { Glycosylated haemoglobin } \\
(\%(S D))^{\star}\end{array}$ & $9 \cdot 5(7 \cdot 7,0 \cdot 25-30)$ & $10 \cdot 4(7 \cdot 9,1-38)$ \\
\hline
\end{tabular}

$\star$ Normal range $<8 \%$.
Table 2 Weighted needle pinprick sensory thresholds in 48 normal control subjects

\begin{tabular}{lcc}
\hline Site & $\begin{array}{c}\text { Mean }(S D) \text { needle } \\
\text { weight }(g)\end{array}$ & Change in mean \\
\hline & First determination & \\
Right hand (RH1) & $0.69(0.32)$ & \\
Left hand (LH1) & $0.68(0.32)$ & RH1 $v$ LH1 1.4\% \\
Right foot (RF1) & $0.88(0.47)$ & \\
Left foot (LF1) & $0.90(0.44)$ & RF1 $v$ LF1 2.3\% \\
& Second determination & \\
Right hand (RH2) & $0.64(0.28)$ & RH1 $v$ RH2 7.2\% \\
Left hand (LH2) & $0.64(0.29)$ & LH1 $v$ LH2 5.9\% \\
Right foot (RF2) & $0.86(0.42)$ & RF1 v RF2 2.3\% \\
Left foot (LF2) & $0.85(0.43)$ & LF1 $v$ LF2 5.5\% \\
\hline
\end{tabular}

^No significant differences between right and left sides or between 1 st and 2 nd determination.

prick sensory thresholds between right and left hand or foot and differences between first and second pinprick threshold determinations. The use of the two sample $t$ test to compare mean sensory thresholds in control subjects and diabetic patients was sometimes inappropriate because of unequal standard deviations. In these cases the differences in thresholds were also evaluated with the Mann Whitney $U$ test. Pearson's simple linear correlation coefficients were calculated for PPT and age, and PPT and duration of diabetes.

\section{Results}

Table 2 shows the percentage change in mean PPT between the first and second threshold determinations, separated by one week, in 48 control subjects. PPT (mean, SD, and 95\% confidence intervals) in the three study groups are compared in table 3 . In the controls mean PPT increased significantly with age in the hand $(r=0.27, p=0.05)$ and foot $(r=0.44$, $\mathrm{p}<0.01$ ). Among the 44 asymptomatic diabetic patients mean PPT on the right hand and foot were both significantly higher than in the controls (table 3). Mean PPT in the asymptomatic diabetic patients increased significantly with age (PPT right hand $\mathrm{r}=0.45, \mathrm{p}<0.002$; PPT right foot $r=0.44, p=0.003$ ) and duration of diabetes (PPT right hand and PPT right foot $r=0.33, p<0.03)$. PPT in the hand and foot of diabetic patients with painful neuropathy differed significantly from controls and asymptomatic diabetic patients (see table 3). There was no significant relation between PPT and age or duration of diabetes in these patients with painful neuropathy (PPT right foot $v$ Age $r=0.25, p=0.14$; PPT right foot $v$ duration of diabetes $\mathrm{r}=-0.08, \mathrm{p}=0.66$ ). Compared with the controls, mean thermal limen from the right hand and foot of diabetic patients with painful neuropathy were significantly elevated (hand $2.3^{\circ} \mathrm{C}, \operatorname{SD} 0.9 v 7.0^{\circ} \mathrm{C}$, SD $4.0, \mathrm{p}<0.001$; foot $6.2^{\circ} \mathrm{C}$, SD $1.8 v$ $19.0^{\circ} \mathrm{C}$, SD 8.8, p < 0.001). There was a significant correlation between PPT and thermal limen at both sites (hand $r=0.24$, $\mathrm{p}<0.05$; foot $=0.41, \mathrm{p}<0.001)$.

\section{Discussion}

The weighted needle apparatus is inexpensive, simple, and rapid to use. The technique is also 
Table 3 Weighted needle pinprick sensory thresholds in 48 control subjects, 44 asymptomatic diabetic patients, and 35 patients with painful diabetic neuropathy

\begin{tabular}{|c|c|c|c|}
\hline & $\begin{array}{l}\text { Controls } \\
(n=48)\end{array}$ & $\begin{array}{l}\text { Asymptomatic diabetic } \\
\text { patients }(n=44)\end{array}$ & $\begin{array}{l}\text { Painful diabetic } \\
\text { neuropathy }(n=35)\end{array}$ \\
\hline $\begin{array}{l}\text { PPT right hand } \\
\text { Mean (SD) (g) } \\
95 \% \text { Confidence interval }\end{array}$ & $\begin{array}{l}0.69(0.32) \\
0.60 \text { to } 0.78\end{array}$ & $\begin{array}{l}0.87(0.44)^{\star} \\
0.74 \text { to } 1.01\end{array}$ & $\begin{array}{l}1.75(1.41)^{\star \star} \\
1.27 \text { to } 2 \cdot 23\end{array}$ \\
\hline $\begin{array}{l}\text { PPT left hand } \\
\text { Mean (SD) (g) } \\
95 \% \text { Confidence interval }\end{array}$ & $\begin{array}{l}0.68(0.30) \\
0.59 \text { to } 0.76\end{array}$ & $\begin{array}{l}0.90(0.40)^{\star} \\
0.78 \text { to } 1.02\end{array}$ & $\begin{array}{l}1.67(1.36)^{\star \star} \\
1.20 \text { to } 2.13\end{array}$ \\
\hline $\begin{array}{l}\text { PPT right foot } \\
\text { Mean (SD) (g) } \\
95 \% \text { Confidence interval }\end{array}$ & $\begin{array}{l}0.88(0.47) \\
0.75 \text { to } 1.02\end{array}$ & $\begin{array}{l}1.12(0.47)^{\star \star \star} \\
0.98 \text { to } 1.27\end{array}$ & $\begin{array}{l}3.62(1.56)^{\star \star} \\
3.08 \text { to } 4.15\end{array}$ \\
\hline $\begin{array}{l}\text { PPT left foot } \\
\text { Mean (SD) (g) } \\
\text { 95\% Confidence interval }\end{array}$ & $\begin{array}{l}0.90(0.44) \\
0.77 \text { to } 1.03\end{array}$ & $\begin{array}{l}1.16(0.59)^{\star \star \star} \\
0.98 \text { to } 1.34\end{array}$ & $\begin{array}{l}3.49(1.56) \star \star \\
2.96 \text { to } 4.03\end{array}$ \\
\hline
\end{tabular}

$\star$ Controls $v$ asymptomatic diabetic patients, $\mathrm{p}=0.03$ ( $t$ test).

$\star \star$ Controls $v$ painful diabetic neuropathy patients, $\mathrm{p}<0.001$ (Mann Whitney $U$ test).

$\star \star \star$ Controls $v$ asymptomatic diabetic patients, $\mathrm{p}<0.01(t$ test $)$. subjects whose pinprick threshold did not increase with age. Previous studies have also shown that some elderly subjects do not show the expected age-related changes in sensory threshold. ${ }^{16}$

In our study, control subjects and diabetic patients without symptoms of neuropathy were carefully matched for age and sex. The diabetic patients with painful neuropathic symptoms were age-matched but contained a higher proportion of men. Pinprick sensory thresholds in the hand and foot, however, were not affected by differences in gender. The sites of pinprick sensory threshold measurement on the dorsum of the hand and foot were carefully chosen to avoid areas of uneven skin thickness. Therefore, we believe that the observed differences between diabetic patients and controls are due predominantly to the presence of peripheral neuropathy in the patient groups. Compared with control subjects, the diabetic patients without symptoms of peripheral neuropathy had significantly higher pinprick sensory thresholds, and the values in both hands and feet correlated with the duration of diabetes and age of these patients. This is consistent with the hypothesis that the duration of hyperglycaemia is important in the development of diabetic neuropathy. ${ }^{17}$ The data also suggest that asymptomatic sensory impairment is fairly common among diabetic patients. Screening for sensory loss may highlight those diabetic patients at risk of developing foot ulceration. ${ }^{3}$ Compared with asymptomatic diabetic patients, patients with painful diabetic neuropathy had considerably higher PPT, implying greater loss of small nerve fibre function, although the duration of diabetes and recent glycaemic control (represented by glycosylated haemoglobin) were similar in the two groups.

Pinprick and cold sensation are believed to be transmitted by small myelinated A-delta fibres whereas warm sensation is transmitted by smaller unmyelinated C-fibres. ${ }^{18}$ Both types of small fibre are important for pain sensibility. The significant correlation between pinprick and thermal thresholds (cold-warm limen) implies that both tests probably give comparable information on dysfunction of small myelinated A-delta nerves. Evaluation of thermal thresholds with Marstock thermostimulators and sophisticated computerised devices requires expensive equipment and is time-consuming. A full evaluation of thermal thresholds with the Marstock equipment in this study took about 45 minutes for each patient and also required a temperature controlled environment. This obviously limits the use of thermal threshold equipment in busy outpatient clinics. In comparison, the pinprick sensory apparatus is inexpensive and allows rapid determination of sensory thresholds.

We thank Novo Laboratories Ltd. for their generous financial support. The weighted needle pinprick sensory apparatus was developed by JAC.

prick sensory threshold values from the foot covered a small range $(0.2$ to $1.15 \mathrm{~g})$. In the over 60 years age group the PPT range was wider $(0.2$ to $2.0 \mathrm{~g})$ and close inspection of the data showed the presence of a subgroup of 
somatic and autonomic neuropathy in patients with different syndromes of diabetic polyneuropathy. Diabetes 1986;35:192-7.

3 Young RJ. Identification of the subject "at risk" of foot ulceration. In: Connor H, Boulton AJM, Ward JD, eds. The foot in diabetes. London: Wiley, 1987:1-10.

4 Parkhouse N, Le Quesne PM. Impaired neurogenic vascular response in patients with diabetes and neuropathic foot lesions. New Engl J Med 1988;318:1306-9.

5 Keele RD. Pain sensitivity tests-pressure algometer. Lancet 1954;i:636-9.

6 Lindblom U. Quantitative testing of sensibility including pain. In: Stalherg E, Young RR, eds. Clinical neurophysiology. London: Butterworths, 1981:168-90.

7 Fruhstorfer H, Lindblom U, Schmidt WG. Method for quantitative estimation of thermal thresholds in patients. J Neurol Neurosurg Psychiatry 1976;39:1071-5.

8 Guy RJC, Clarke CA, Malcolm PN, Watkins PJ. Evaluation of thermal and vibration sensation in diabetic neuropathy. Diabetologia 1985;28:131-7.

9 Jamal GA, Hansen S, Weir AI, Ballantyne JP. An improved automated method for the measurement of thermal thresholds. 1. Normal subjects. JNeurol Neurosurg Pyschiat 1985;48:354-60.

10 Bertelsmann FW, Heimans JJ, Weber EJM, van der Veen EA. Thermal discrimination thresholds in normal subjects and in patients with diabetic neuropathy. JNeurol
Neurosurg Psychiat 1985;48:686-90.

11 Fagius J, Wahren LK. Variability of sensory threshold determination in clinical use. J Neurol Sci 1981;51:11-27.

12 Williams G, Gill JS, Aber V, Mather HM. Variability in vibration perception threshold among sites: a potential vibration perception threshold among sites: a potential
source of error in biothesiometry. Br Med $J$ 1988;296: 233-5.

13 Lahuerta J, Campbell JA, Dewshi F. Dolor isquemico muscular. Efects de "entranmiento" tras realizacion repetida de un test experimental. Rev Med Univ Navarra 1983;27:161-5

14 Dyck PJ, Karnes J, O'Brien PC, Zimmermann IR. Quantitation of cutaneous sensation in man. In: Dyck PJ, Thomas PK, Lamber EW, Bunge R, eds. Peripheral neuropathy. Philadelphia: Saunders, 1984:1103-8.

15 Vital A, Vital C, Rigal B, Decamps A, Emeriau JP, Galley P. Morphological study of the ageing human peripheral nerve. Clin Neuropathology 1990;9:10-5.

16 Tucker MA, Andrew MF, Ogle SJ, Davison JG. Ageassociated change in pain threshold measured by trancutaneous neuronal electrical stimulation. Age Ageing 1989;18:241-6.

17 Pirart J. Diabetes mellitus and its degenerative complications, a prospective study of 4400 patients between 1947 tions, a prospective study of 4400 patients between

18 Bowsher D. Recent anatomical contributions to the understanding of pain. Clin Anat 1988;1:157-70. 